\title{
Modeling of methane formation in gravity sewer system: the impact of microorganism and hydraulic condition
}

\author{
Jingwei $\mathrm{Xu}^{1}$, Qiang $\mathrm{He}^{2}$, Hong $\mathrm{Li}^{2}$, Chun Yang ${ }^{2}$, Yinliang Wang ${ }^{3}$ and Hainan $\mathrm{Ai}^{2 *}$
}

\begin{abstract}
Sewer system is an important source of methane formation and emission. Although some models were developed to predict methane production in sewers, the impact of microorganism amount was indicated indirectly. Here, seven laboratory scale sewers with varied wall-shear stresses were established. The biofilm thickness, microorganism amount, DO distribution, microorganism community in the biofilms and methane production in the sewers were measured. Based on experimental data, an empirical model was developed to directly describe the relationship between methane production, microorganism amount and wall-shear stress. The results showed that DO concentration decreased significantly along the biofilm depth under varied wall-shear stress, and the DO reduction rate was positively related to the intensity of wall-shear stress. The dominant archaea species in mature biofilms were similar whereas the proportions showed remarkable differences. The abundance of Methanospirillum in biofilms cultured at $2.0 \mathrm{~Pa}$ wall-shear stress was $53.08 \%$ more than that at $1.29 \mathrm{~Pa}$. The maximum methane production rate, $2.04 \mathrm{mg} / \mathrm{L}$ wastewater day, was obtained when the wall-shear stress kept at $1.45 \mathrm{~Pa}$, which was 1.2-fold higher than the minimum in sewer at $0.5 \mathrm{~Pa}$. The $\mathrm{R}^{2}$ value of the established model was 0.95 , the difference between the measurement and simulation was in the rage of $1.5-13.0 \%$.
\end{abstract}

Keywords: Sewers, Wall-shear stress, Methane production, Microorganism, Model

\section{Introduction}

The control of methane emission have received global considerations. Previous studies were mostly focused on methane emissions from wetlands, termites, ruminants, rice agriculture, fossil fuel exploitation, landfills and biomass burning (Sawakuchi et al. 2016; Weller et al. 2016; Zhao et al. 2016). However, another potential source of methane emission, sewers, was not paid adequate attentions. Methane emission from sewage treatment was found to constitute approximately $5 \%$ of the global methane sources (El-Fadel and Massoud 2001). For example, according to National Bureau of Statistics of China, there were 540,000 km sewers in China till 2015 and the average annual growth rate was $7.0 \%$ in recent 3 years. In

\footnotetext{
*Correspondence: aihainan@126.com

2 Key Laboratory of the Three Gorges Reservoir Region's Eco-Environment, Ministry of Education, Chongqing University, Chongqing 400045, People's Republic of China

Full list of author information is available at the end of the article
}

addition, more than $95 \%$ of the sewers are gravitational. And a large amount of methane can be produced in gravity sewers and diffused into the atmosphere through manhole. Therefore, controlling methane emission from sewers has a great significance for global climate change.

Recently, some researchers were devoted to studying the reduction of methane in sewers, mainly using chemicals, such as ferric iron (Zhang et al. 2009), nitrate (Jiang et al. 2013) and oxygen injection (Ganigue and Yuan 2014). Although most of these chemicals can inhibit methane production in sewers effectively, they were usually costly and accompanied by some additional problems to subsequent treatment such as increased sludge (Ganigue et al. 2011; Sharma et al. 2012). Methane can be formed in sewers as a result of methanogenic archaea (MA) metabolism (Guisasola et al. 2008). Hydraulic conditions can affect the biofilm's structure and biological community in sewers (Laspidou and Rittmann 2004; Rochex et al. 2008) hence had a great impact on the 
formation and emission of methane. This indicated that the methane production could be controlled through manipulation of hydraulic conditions, in an environmental-friendly and cost- effective way. In order to study methane production in sewers quantitatively, previous studies had developed empirical models. Foley et al. (2009) developed an empirical model (Eq. 1) for estimating methane emissions from rising main sewer systems _ENREF_14.

$$
C_{\mathrm{CH}_{4}}=5.24 \times 10^{-5} \cdot\left[\frac{A}{V} \times H R T\right]+0.0015
$$

where $\mathrm{C}_{\mathrm{CH}_{4}}$ is the mass $\mathrm{CH}_{4}$ emission per unit volume of wastewater $\left(\mathrm{kg} / \mathrm{m}^{3}\right), \mathrm{A} / \mathrm{V}$ is the surface area to volume ratio of sewer, $\left(\mathrm{m}^{-1)}\right.$ and HRT is wastewater retention time in sewer (h).

Despite the fact that the results of model fitted well with field data, the influence of wastewater temperature, which was essential to methane formation, was neglected in the model. Consequently, Chaosakuo et al. (2014) developed another empirical model based on the Foley's model for predicting $\mathrm{CH}_{4}$ emission from gravity-flow sewers located in tropical areas of developing countries (Eq. 2)_ENREF_15.

$C_{C_{4}}=6 \times 10^{-5} \cdot 1.05^{(T-20)} \cdot\left[\frac{A}{V} \times H R T\right]+0.0015$

where $\mathrm{T}$ is the temperature of sewer wastewater, ${ }^{\circ} \mathrm{C}$.

In Chaosakuo's model, the wastewater temperature was taken into consideration in comparison to Foley's model, however, the $\mathrm{R}^{2}$ value of model was rather low (0.06). In Chaosakuo's opinion, it may be the limitation of (A/V) HRT, leakages of methane and variation of the climatic conditions that caused the rather low $\mathrm{R}^{2}$ value.

The above models were significant to calculate methane production in sewers and both considered the A (surface area of the biofilm), but the effect of microorganism which played the main role in methane formation was overlooked. In fact, methane can be formed as the result of MA metabolism (Guisasola et al. 2008) and maybe it is more reasonable to take into account the amount of microorganism instead of A in gravity sewers.

In this study, the simulated sewers with varied wallshear stresses were established under laboratory scales. In the simulated sewers, the structure and composition of sewer biofilms were investigated, the DO distribution were evaluated and the methane emission in sewers were assessed as well. The objective of this study is to explain how wall-shear stress affect the methane emission and establish a more solid model to describe or predict methane emission from gravity sewers.

\section{Materials and methods}

\section{Construction and operation of simulated sewers}

A well-controlled pilot system (Fig. 1) was set up to simulate the practical operation of sewers. Seven PVC (Poly Vinyl Chloride) sewers with identical size (with $8.0 \mathrm{~m}$ length, $57.0 \mathrm{~mm}$ inner diameter and $\mathrm{I}=8 \%$ ) were placed and operated in parallel under the wall-shear stresses of $0.5,0.8,1.12,1.29,1.45,2.0$ and $2.5 \mathrm{~Pa}$. The value of wall-shear stress was obtained by combining particle image velocity (PIV) and the Fluent, based on our previous study (Ai et al. 2016). Firstly, the distribution information of the flow field was obtained by PIV. Secondly, the distribution information of the flow field at the same conditions was obtained by modeling used the Fluent and optimizing the parameters. Lastly, the wall shear stress was calculated by the model result of Fluent and the relationship between the shear stress and the factors which affect the flow was established as Eq. 3.

$$
\begin{aligned}
\mathrm{F}= & 0.21941+0.44146 I+1.73331 n-0.52041 v \\
& +0.13167 n I-0.24688 v I-1.47281 n v \\
& +0.23833 I^{2}-0.12750 n^{2}+1.88828 v^{2}
\end{aligned}
$$

where $\mathrm{F}$ is the wall-shear stress, $\mathrm{Pa}$; I is the slope of sewers, \%; $\mathrm{n}$ is the fullness degree of sewers; $\mathrm{v}$ is the velocity of flow, $\mathrm{m} / \mathrm{s}$.

Synthetic sewage that added into the seven sewers was prepared in an elevated PVC tank $(20.0 \mathrm{~L})$ with the water temperature maintained in the range of $20.0-25.0{ }^{\circ} \mathrm{C}$, which was similar to temperature in real sewers. According to our actual monitoring, the $\mathrm{pH}$ was maintained within 7.0-7.5, similar to which was in the real sewer in this study. And $\mathrm{pH}$ in this rage is favorable for the growth of methanogen. The $\mathrm{pH}$ was tested every day. According to the daily test results, the $\mathrm{pH}$ was regulated using $\mathrm{HCl}$ or $\mathrm{NaHCO}_{3}$ and maintained at 7.0-7.5. The outflows were then collected by seven PVC tanks and pumped back to the elevated tank operated $24 \mathrm{~h} /$ day. PVC chips $(3.0 \times 3.0 \mathrm{~cm})$ were installed on the sewer inner-wall below water and they can be removed for regular measurement of thickness of the developed biofilms. A synthetic sewage (Glucose: $375 \mathrm{mg} / \mathrm{L} ; \mathrm{NH}_{4} \mathrm{Cl}$ : $114.6 \mathrm{mg} / \mathrm{L} ; \mathrm{NaH}_{2} \mathrm{PO}_{4} \cdot 2 \mathrm{H}_{2} \mathrm{O}: 50.3 \mathrm{mg} / \mathrm{L} ; \mathrm{MgSO}_{4} \cdot 7 \mathrm{H}_{2} \mathrm{O}$ : $180 \mathrm{mg} / \mathrm{L} ; \mathrm{KCl}: 72 \mathrm{mg} / \mathrm{L} ; \mathrm{CaCl}_{2}: 10.6 \mathrm{mg} / \mathrm{L} ;$ Peptone: $5 \mathrm{mg} / \mathrm{L} ; \mathrm{NaHCO}_{3}: 225 \mathrm{mg} / \mathrm{L} ; \mathrm{FeCl}_{3} \cdot 6 \mathrm{H}_{2} \mathrm{O}: 375 \mathrm{mg} / \mathrm{L}$; $\mathrm{MnCl}_{2} \cdot 4 \mathrm{H}_{2} \mathrm{O}: 30 \mathrm{mg} / \mathrm{L} ; \mathrm{H}_{3} \mathrm{BO}_{3}: 37.5 \mathrm{mg} / \mathrm{L} ; \mathrm{ZnSO}_{4} \cdot 7 \mathrm{H}_{2} \mathrm{O}$ : $30 \mathrm{mg} / \mathrm{L} ; \mathrm{CuSO}_{4} \cdot 5 \mathrm{H}_{2} \mathrm{O}: 7.5 \mathrm{mg} / \mathrm{L}$; EDTA: $30 \mathrm{mg} / \mathrm{L}$; KI: $45 \mathrm{mg} / \mathrm{L}$ ) was used, according to previous research (Smolders et al. 1994). There were two main reasons for using synthetic sewage. One reason was that it could ignore the effect of inorganic substance when the amount of microorganism was discussed. The another 


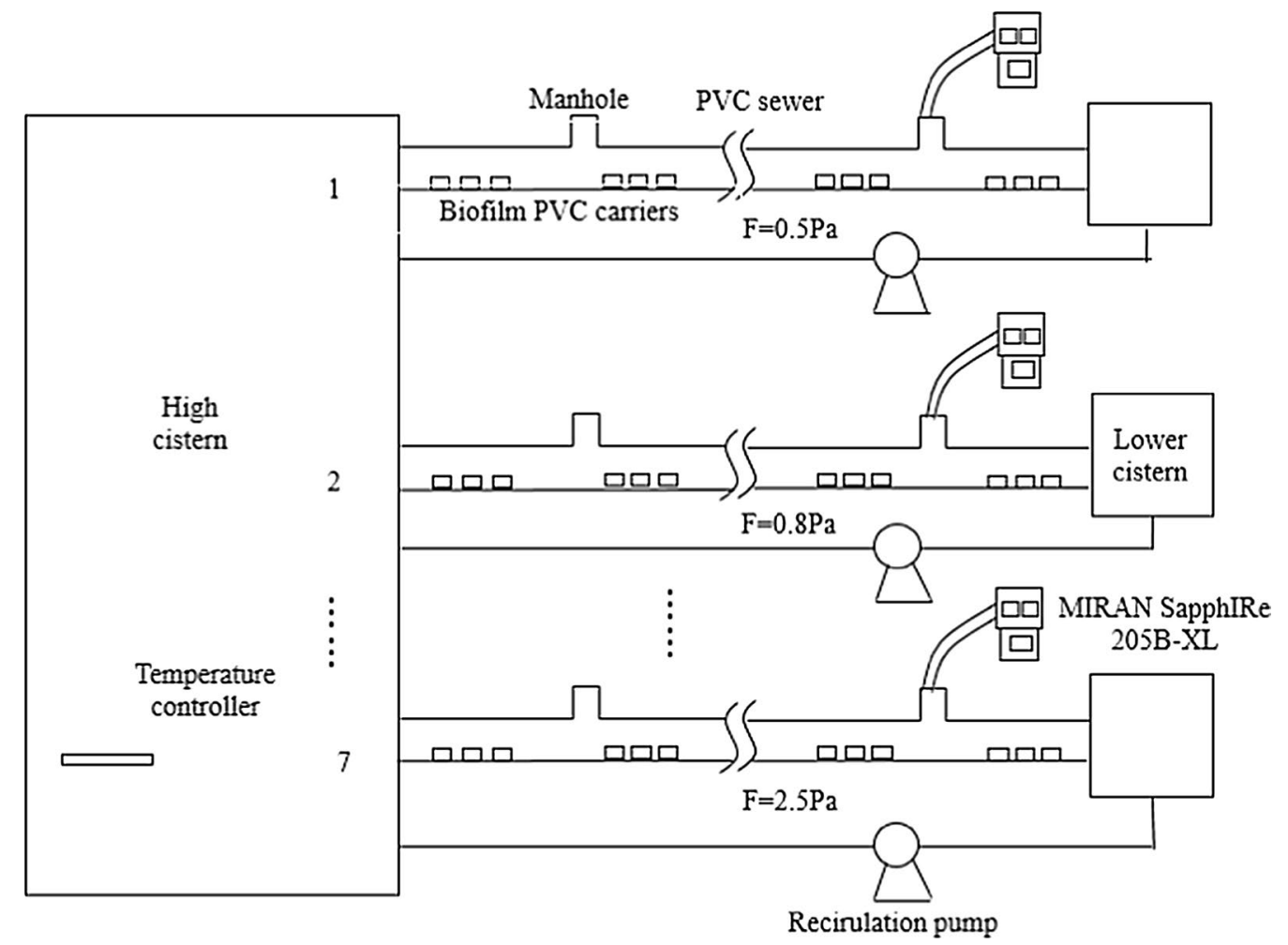

Fig. 1 Layout of the pilot gravitational sewers and the sectional view. A well-controlled pilot system was set up to simulate the practical operation of sewers. Seven PVC (Poly Vinyl Chloride) sewers with identical size (with $8.0 \mathrm{~m}$ length, $57.0 \mathrm{~mm}$ inner diameter and I= 8\%) were placed and operated in parallel under the wall-shear stresses of $0.5,0.8,1.12,1.29,1.45,2.0$ and 2.5 Pa. Synthetic sewage that added into the seven sewers was prepared in an elevated PVC $\operatorname{tank}(20.0 \mathrm{~L})$ with the water temperature maintained in the range of $20.0-25.0^{\circ} \mathrm{C}$, which was similar to temperature in real sewers. According to our actual monitoring, the $\mathrm{pH}$ was maintained within 7.0-7.5, similar to which was in the real sewer in this study. The outflows were then collected by seven PVC tanks and pumped back to the elevated tank operated $24 \mathrm{~h} /$ day. PVC chips $(3.0 \times 3.0 \mathrm{~cm})$ were installed on the sewer inner-wall below water and they can be removed for regular measurement of thickness of the developed biofilms

reason was that there was microorganism in real sewage, if the real sewage was used, the portion of methane may be produced by the microorganism in the sewage and it would have an important effect on the methane production.

The experiment was conducted under the initial COD concentration of 400 and $200 \mathrm{mg} / \mathrm{L}$, respectively. The COD in the two group was measured every day and then was supplemented to the initial concentration according to the measured concentration.

\section{Biofilm characterization}

The biofilm thickness and total solids (TS), extracellular polymeric substances (EPS), along with DO distribution in biofilm were assessed in order to evaluate growth of biofilm and determine the time of biofilm maturity (Ai et al. 2016), which could provide a basis for collecting methane and calculating microbial biomass. When the biofilm thickness was stable and the biofilm growth and sloughing were in equilibrium, it was considered to be mature.

\section{Biofilm thickness}

The biofilm thickness was measured with microelectrodes (Unisense company, Denmark). The tip diameter was $10 \mu \mathrm{m}$. In the process of experiment, the LS18 bracket, microelectrode thruster (MM33-2) and motor controller from Unisense company were used. The step distance of $\mu \mathrm{m}$ was achieved by the MM33-2. The electrical signal produced by microelectrode was collected by Microsensor Multimeter and read through the software PRO V.3.1.3 SensorTrace. The oxygen measurement was detailed as follows. In the process of biofilm growth, PVC chips were removed from the sewers to measure biofilm thickness every 5 days. When the micro-electrodes began to get into the biofilm, it began to measure. And when the micro-electrodes started to bend, the measurement was completed. Due to the heterogeneity of the local 
biofilms, biofilm thickness of nine typical points on each chip was measured and the obtained average value was then regarded as the calculated biofilm thickness.

\section{Total solids}

The chips having been measured for biofilm thickness were placed in ultra-pure water, produced by Simplicity UV (HACH company, USA) and subjected to $40.0 \mathrm{~W}$ ultrasound treatment for $1 \mathrm{~min}$ at $20 \mathrm{kHz}$. The pulp was then homogenized and measured by gravimetric method.

\section{EPS}

The EPS was measured using the method described in our previous research (Xin et al. 2016).

\section{DO distribution}

After the maturation of biofilms, the DO in the biofilms were measured with the DO microelectrode (OX10). Firstly, the DO micro-electrode was connected to the pA channel and polarized, until the stability of signal. Secondly, ran the software STPRO and relevant parameters were set. Thirdly, A standard curve of oxygen concentration was obtained based on oxygen concentration of zero and saturation. Finally, the oxygen in the biofilm was measured with 3-s response time and $100 \mu \mathrm{m}$ per step. Its response time was less than 3-s and the agitation sensitivity was low.

\section{Microorganism communities}

When anoxic biofilms were fully developed in the pilot sewers, the biofilm samples taken from the chip were then transferred to $2.0 \mathrm{~mL}$ plastic centrifuging vials and transported to Sangon Biotech (Shanghai) Co., Ltd for the analysis of microorganism communities using high throughput sequencing (HTS). Plenty of ice cubes were used during sample transportation to avoid the degradation of samples. DNA extraction, PCR amplification and sequencing were all conducted by Sangon Biotech (Shanghai) Co. The composition of the PCR products of $16 \mathrm{~S}$ rRNA gene was determined by pyrosequencing using the Roche 454 GS-FLX Titanium sequencer (Roche 454 Life Sciences, Branford, CT, USA). Samples in this study were individually barcoded to enable multiplex sequencing. The results are deposited into the NCBI short reads archive database. The accession was Bioproject PRJNA419305 (SRP125386). Details can be seen in our recent articles (Ai et al. 2016).

\section{Methane production}

When anoxic biofilms were fully developed in the pilot sewers after 45 days, the generated methane from the simulated sewer was collected and measured using a Shimadzu GC-9A Gas Chromatograph equipped with an FID once every hour and lasted for 6 days. According to methane concentration every hour and sewers volume, methane production was calculated in sewer every day.

\section{Model establishing}

Based on previous models, a model establishing the relationships between methane emission and microorganism amount, along with methane emission and wall-shear stress in gravity sewers was developed. The model was operated with the experiment results under COD concentration of $400 \mathrm{mg} / \mathrm{L}$ and was validated with the experiment results under COD concentration of $200 \mathrm{mg} / \mathrm{L}$.

\section{Results}

In this study, biofilm thickness, density, microbial community and DO distribution were used to describe the sewer biofilm structure, which presented similar trends at seven wall-shear stresses, therefore, the biofilm structures were analyzed and compared at three representative wall-shear stresses $(\mathrm{F}=0.8,1.29$ and $2.0 \mathrm{~Pa})$.

\section{The biofilm growth}

The biofilm thicknesses and biomass densities variation over time at three shear stress levels were showed on Figs. 2 and 3. At different shear stresses, biofilm thickness changes according to a similar pattern. Firstly, biofilm thickness reached a maximum value within $0-25$ days. Then, within 5-10 days after the thickness reaches its maximum value, the thickness of the biofilm decreases to

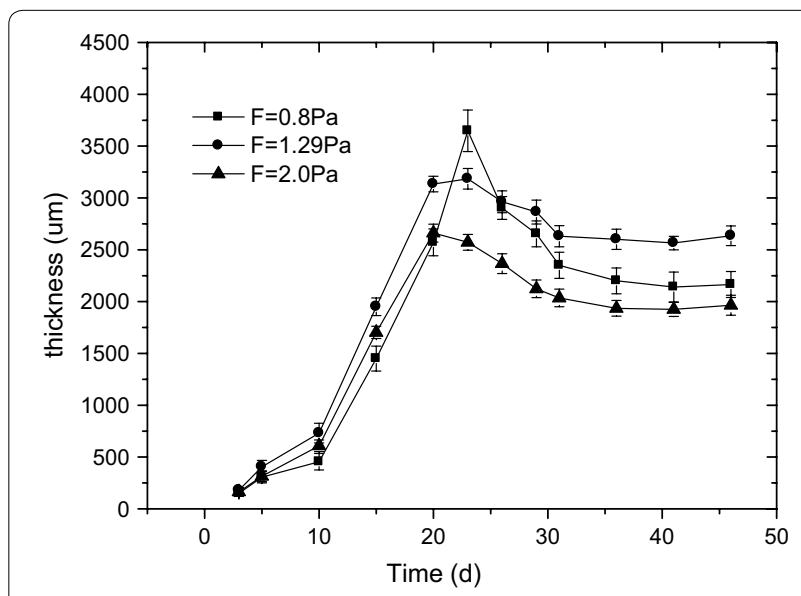

Fig. 2 Biofilm thickness versus time at different wall-shear stresses, $\mathrm{COD}=400 \mathrm{mg} / \mathrm{L}$ ( $\mathrm{F}$ means wall-shear stress, Pa). At different shear stresses, biofilm thickness changes according to a similar pattern. Firstly, biofilm thickness reached a maximum value within 0-25 days. Then, within 5-10 days after the thickness reaches its maximum value, the thickness of the biofilm decreases to a certain extent. Finally, biofilm thickness tended towards stability. Under the conditions of this experiment, the thicknesses of the biofilms were $2.4 \pm 0.1,2.7 \pm 0.1$ and $2.2 \pm 0.1 \mathrm{~mm}$ at shear stresses of $0.8,1.29$ and $2.0 \mathrm{~Pa}$, respectively 


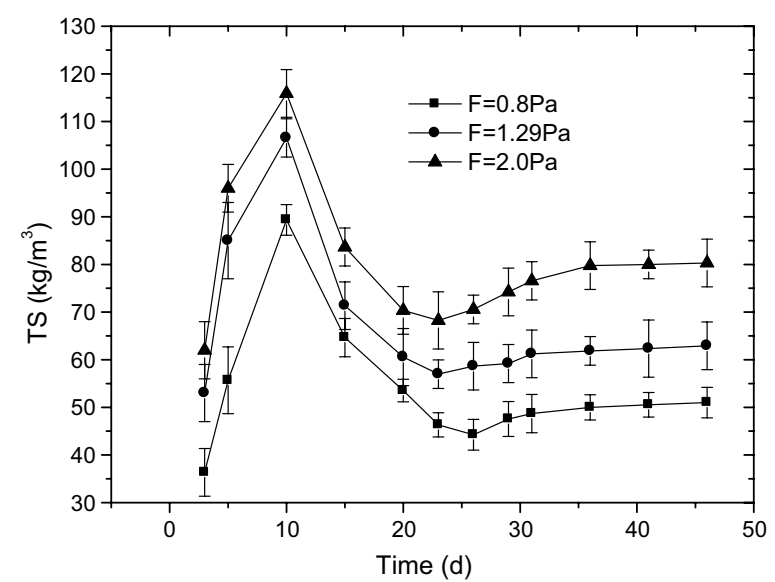

Fig. 3 Variation of biomass density at different wall-shear stresses; $\mathrm{COD}=400 \mathrm{mg} / \mathrm{L}$ (F means wall-shear stress, Pa). At three wall-shear stresses of $0.8,1.29$ and $2.0 \mathrm{~Pa}$, the average biofilm densities were $51 \pm 3,62 \pm 5$ and $80 \pm 5 \mathrm{~kg} / \mathrm{m}^{3}$, respectively, indicating that the average biofilm densities increased with the increase of wall-shear stress

a certain extent. Finally, biofilm thickness tended towards stability. Under the conditions of this experiment, the thicknesses of the biofilms were $2.4 \pm 0.1,2.7 \pm 0.1$ and $2.2 \pm 0.1 \mathrm{~mm}$ at shear stresses of $0.8,1.29$ and $2.0 \mathrm{~Pa}$, respectively. Three mature biofilms (biofilm thickness was stable) were obtained after approximately 45 days. At three wall-shear stresses of $0.8,1.29$ and $2.0 \mathrm{~Pa}$, the average biofilm densities were $51 \pm 3,62 \pm 5$ and $80 \pm 5 \mathrm{~kg} /$ $\mathrm{m}^{3}$, respectively, indicating that the average biofilm densities increased with the increase of wall-shear stress.

\section{DO distribution in biofilms}

The changes of DO along the biofilm depth under three wall-shear stresses were showed in Fig. 4. Under three conditions, the DO fell along the biofilm depth and eventually decreased to zero. At the wall-shear stressed of 0.8, 1.29 and 2.0 Pa, the biofilm thicknesses where the dissolved oxygen reduced to zero were 2050, 1850 and $1450 \mu \mathrm{m}$, respectively. It revealed that the reduction rate of dissolved oxygen was positively correlated with the wall-shear stress.

\section{The archaea}

The sequences of biofilms at three wall-shear stresses $(0.8,1.29,2.0 \mathrm{~Pa})$ were 19,326, 17,848 and 9458, the operational taxonomic units (OTUs) were 52, 20 and 10 , respectively. The coverage of biofilm samples were all $99.9 \%$, indicating that the results were reasonable and could reflect the microbial community structure of biofilm samples.

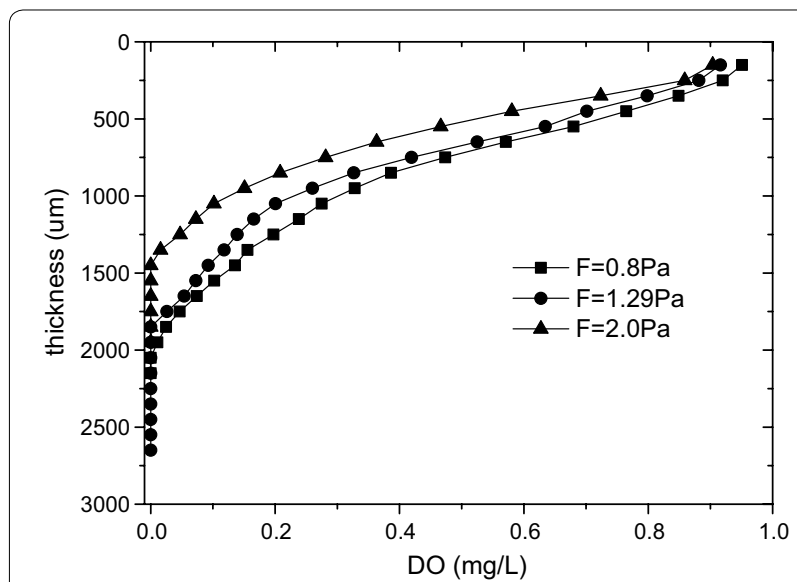

Fig. 4 Changes of dissolved oxygen in the biofilm with biofilm thickness, $C O D=400 \mathrm{mg} / \mathrm{L}$. The changes of DO along the biofilm depth under three wall-shear stresses were showed. Under three conditions, the DO fell along the biofilm depth and eventually decreased to zero. At the wall-shear stressed of 0.8, 1.29 and 2.0 Pa, the biofilm thicknesses where the dissolved oxygen reduced to zero were 2050, 1850 and $1450 \mu \mathrm{m}$, respectively. It revealed that the reduction rate of dissolved oxygen was positively correlated with the wall-shear stress

Nine classified archaea were detected and listed in Fig. 5 and Table 1. Methanospirillum and DHVEG-6 were both dominant in three biofilms. They both accounted for 96.02, 99.6 and $99.6 \%$, respectively, at wall-shear stresses of $0.8,1.29$ and 2.0 Pa. The proportion of methanospirillum in this study increased with the increase of wall-shear stress, but DHVEG-6 was decreased with the increase of wall-shear stress.

\section{Laboratory-scale methane production}

The methane production was shown in Fig. 6. At seven wall-shear stresses, the average methane production were $0.93,1.32,1.63,1.80,2.04,1.93$ and $1.48 \mathrm{mg} /$ (L wastewater day), respectively. Methane production increased with the increase of wall-shear stress until the wall-shear stress reached $1.45 \mathrm{~Pa}$. The maximum methane production was $2.04 \mathrm{mg} /(\mathrm{L}$ wastewater day) and the minimum methane production was $0.93 \mathrm{mg} /(\mathrm{L}$ wastewater day).

\section{Discussion}

The effect of wall-shear stress on biofilm physical structure Previous works have reported that higher shearing stresses led to thinner biofilms (Kwok et al. 1998; Laspidou and Rittmann 2004; Liu and Tay 2002). However, as shown in Fig. 2, the biofilm thickness obtained in this study increased from 2.1 to $2.7 \mathrm{~mm}$ while the wall-shear stress increased 0.8 and $1.29 \mathrm{~Pa}$. This may because the range of wall-shear stresses and the structure of pilot sewers were different from which used in the previous research. In the study of Liu and Tay, the shear stresses 


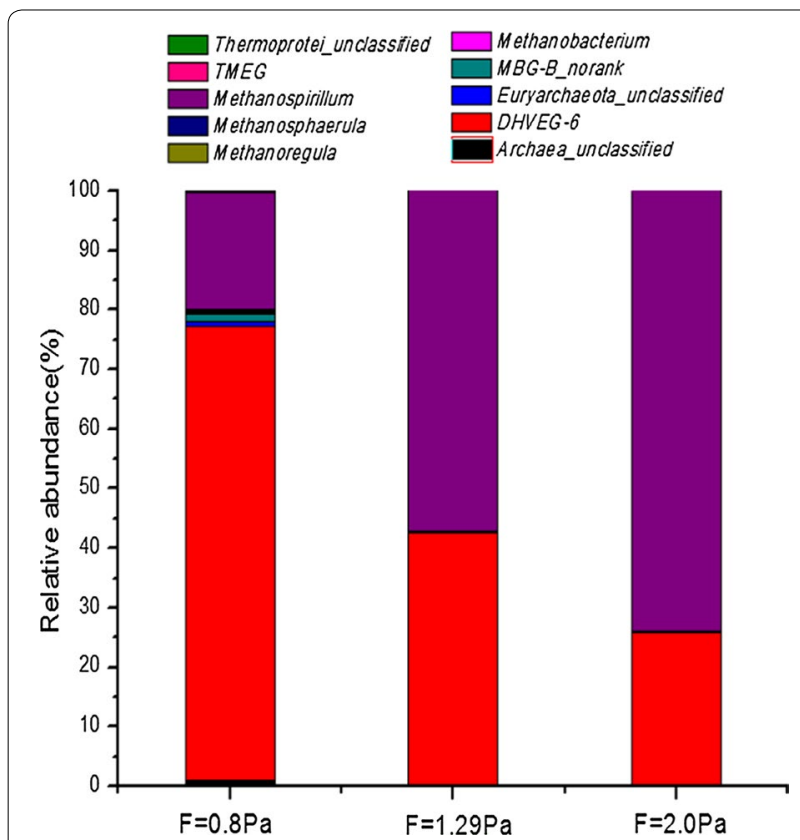

Fig. 5 The relative abundance of predominant bacterial phylum in mature biofilms, $C O D=400 \mathrm{mg} / \mathrm{L}$. Nine classified archaea were detected and listed in Table 1. Methanospirillum and DHVEG-6 were both dominant in three biofilms. They both accounted for 96.02, 99.6 and $99.6 \%$, respectively, at wall-shear stresses of $0.8,1.29$ and $2.0 \mathrm{~Pa}$. The proportion of methanospirillum in this study increased with the increase of wall-shear stress, but DHVEG-6 was decreased with the increase of wall-shear stress

Table 1 The relative abundance of predominant bacterial phylum in mature biofilms, COD $=\mathbf{4 0 0} \mathrm{mg} / \mathrm{L}$

\begin{tabular}{lcll}
\hline & $\mathbf{F}=\mathbf{0 . 8} \mathbf{P a}$ & $\mathbf{F}=\mathbf{1 . 2 9} \mathbf{P a}$ & $\mathbf{F}=\mathbf{2 . 0} \mathbf{~ P a}$ \\
\hline Archaea_unclassified (\%) & 0.97 & 0.02 & 0.01 \\
DHVEG-6 (\%) & 76.15 & 42.53 & 25.76 \\
Euryarchaeota_unclassified (\%) & 0.89 & 0.09 & 0.01 \\
MBG-B_norank (\%) & 1.25 & 0.23 & 0.03 \\
Methanobacterium (\%) & 0.26 & 0.02 & 0 \\
Methanoregula (\%) & 0.4 & 0.04 & 0.32 \\
Methanosphaerula (\%) & 0.04 & 0 & 0.01 \\
Methanospirillum (\%) & 19.87 & 57.07 & 78.84 \\
TMEG (\%) & 0.06 & 0 & 0.02 \\
Thermoprotei_unclassified (\%) & 0.11 & 0 & 0 \\
\hline
\end{tabular}

were 6.5-9.0 Pa. In the study of Kwok, the biofilms were formed in 3-L internal loop airlift reactors. However, our results were supported by the study of Guzmán et al. (2007) which has demonstrated that the wall-shear stress within the range of 1.1-1.4 Pa was suitable for biofilm growth in sewers_ENREF_19. Biofilm density was impacted by some factors including hydraulic condition and microbial species (Christensen and Characklis

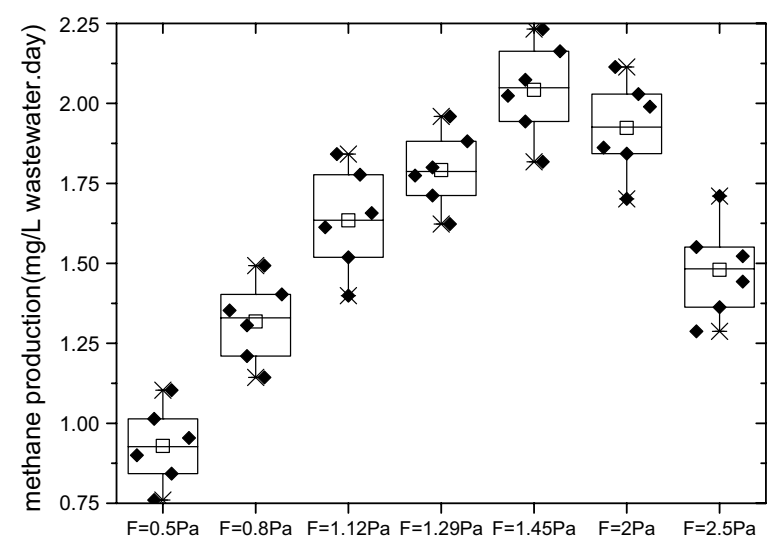

Fig. 6 Methane production at different wall-shear

stresses, $C O D=400 \mathrm{mg} / \mathrm{L}$. The methane production was shown. At seven wall-shear stresses, the average methane production were 0.93 , $1.32,1.63,1.80,2.04,1.93$ and $1.48 \mathrm{mg} /(\mathrm{L}$ wastewater day), respectively. Methane production increased with the increase of wall-shear stress until the wall-shear stress reached $1.45 \mathrm{~Pa}$. The maximum methane production was $2.04 \mathrm{mg} /(\mathrm{L}$ wastewater day) and the minimum methane production was $0.93 \mathrm{mg} /(\mathrm{L}$ wastewater day)

1990) (Laspidou and Rittmann 2004). The wall-shear stress affects the biofilms horizontally and vertically. The loose surface of biofilm would be washed away and the attached biofilms were compressed by the increase of wall-shear stress, leading to the increase of the biomass density (Xu et al. 2016). The higher density observed at higher wall-shear stress in this study was supported by others' research (Liu and Tay 2002; Vieira et al. 1993), that a higher wall-shear stress resulted in a denser biofilm was founded in their studies.

Porosity and density of biofilm are both important to the transformation in biofilm. According to our previous research, the oxygen penetration depth in biofilm was higher in lower wall-shear stress (Xu et al. 2016). The greater wall-shear stress was, the greater the density of biofilm was. In other words, a denser biofilm under higher shear stress could lead to the decreased oxygen penetration depth. Previous studies have shown that slight shearing stress was favorable for the formation of the inattentive and porous structure of biofilm (van Loosdrecht et al. 1995, 2002). Because biofilm porosity decreased with the increase of wall-shear stress, the dissolved oxygen was minimum in the biofilm cultured at wall-shear stress of $2.0 \mathrm{~Pa}$ among these three wall-shear stresses. Oxygen played a significant role in the process of microbial growth and the different oxygen conditions inevitably had a major impact on the microbial community structure of the biofilms.

The effect of wall-shear stress on biofilm structure was in three aspects. Firstly, with the increase of wall-shear 
stress, biofilm became thinner. Then, with the increase of wall-shear stress, biofilm density became greater. Lastly, the microbial community in biofilm was affected by wallshear stress (Cheng et al. 1997).

\section{The effect of wall-shear stress on biofilm microbial structure \\ The microorganism amount}

Biofilm is a complex micro-ecological structure composed of microorganisms and EPS. Flow rate, the diameter of sewer (Guzmán et al. 2007) and substrate concentration were important factors affecting biofilm growth in sewers. In this study, wall-shear stress was calculated by combining flow rate, slope and fullness, which can be seen as a comprehensive factor. Due to the use of synthetic sewage, the inorganic materials in the biofilms were few thus could be ignored. The average mass density of the biofilm (TS) which did not consist of Extracellular Polymeric Substances (EPS) could represent the microorganism quantity. The amount of microorganism was calculated according to the average biofilm density, thickness, the surface area of biofilm growth and the EPS. As show in Fig. 7, the amount of microorganism increased with the increase of wall-shear stress until the wall-shear stress reached $1.45 \mathrm{~Pa}$. When wall-shear stress exceeded $1.45 \mathrm{~Pa}$, although the biofilm density increased as well, the thickness of biofilm decreased at a greater degree,

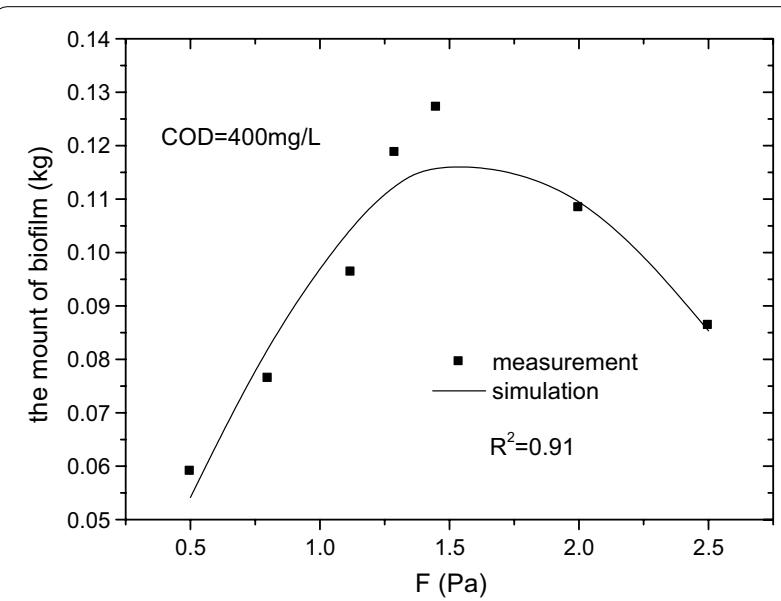

Fig. 7 Microorganism amount vs wall-shear stress, $C O D=400 \mathrm{mg} / \mathrm{L}$. The amount of microorganism increased with the increase of wall-shear stress until the wall-shear stress reached 1.45 Pa. When wall-shear stress exceeded $1.45 \mathrm{~Pa}$, although the biofilm density increased as well, the thickness of biofilm decreased at a greater degree, resulting the drop of the microorganism amount. When the wall-shear stress was $1.45 \mathrm{~Pa}$, the average biofilm density was $74 \pm 5 \mathrm{~kg} / \mathrm{m}^{3}$, just $7.5 \%$ less than which obtained at wall-shear stress of $2.0 \mathrm{~Pa}$, while the biofilm thickness was $2.4 \pm 0.1 \mathrm{~mm}, 20.8 \%$ greater than which reached at wall-shear stress of $2.0 \mathrm{~Pa}$. The $\mathrm{R}^{2}$ of Eq. (3) was 0.91 , indicating that it is reasonable resulting the drop of the microorganism amount. When the wall-shear stress was $1.45 \mathrm{~Pa}$, the average biofilm density was $74 \pm 5 \mathrm{~kg} / \mathrm{m}^{3}$, just $7.5 \%$ less than which obtained at wall-shear stress of $2.0 \mathrm{~Pa}$, while the biofilm thickness was $2.4 \pm 0.1 \mathrm{~mm}, 20.8 \%$ greater than which reached at wall-shear stress of $2.0 \mathrm{~Pa}$.

According to the calculated data, a simple empirical model (Eq. 4) about microorganism and wall-shear stress was developed

$$
\mathrm{X}=-0.0485 F^{2}+0.161 F-0.0142
$$

where $\mathrm{X}$ is the amount of microorganism $(\mathrm{kg})$; $\mathrm{F}$ is wallshear stress $(\mathrm{Pa})$.

As shown in Fig. 7, the $\mathrm{R}^{2}$ of Eq. (4) was 0.91, indicating that it is reasonable. In addition, in order to validate the model, the measured data was used when COD was $200 \mathrm{mg} / \mathrm{L}$. As the Fig. 8 shown, the $\mathrm{R}^{2}$ was 0.90 .

\section{The effect of wall-shear stress on microbial composition}

The wall-shear stress influenced the mass transfer in biofilm and it played an important role in the microbial composition of the biofilm. Previous research was mostly focused on the influence of wall-shear stress on the physical structure such as biofilm thickness and biofilm density (Kwok et al. 1998; Liu and Tay 2002). However, the impact of wall-shear stress on the biofilm microbial composition did not obtain enough attention (Rochex et al. 2008). As shown in Fig. 5, although Deep-Sea-Hydrothermal-Vent-Gp-6 (DHVEG-6)-norank6 and Methanospirillum were the dominant bacteria in three biofilms, their proportions were different. DHVEG-6 is known as haloarchaea, distantly related to halobacteriales, (Casamayor et al. 2013) and has been detected in marine

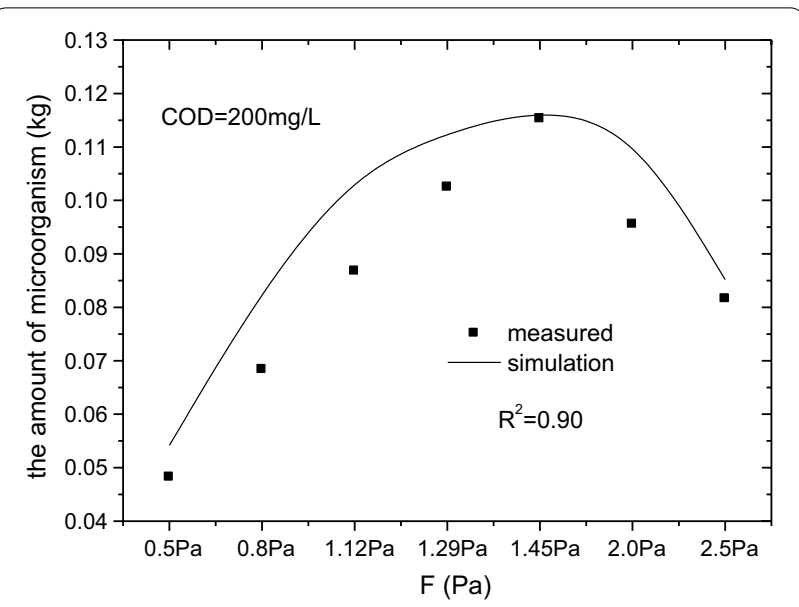

Fig. 8 Microorganism amount vs wall-shear stress, COD $=200 \mathrm{mg} / \mathrm{L}$. In addition, in order to validate the model, the measured data was used when COD was $200 \mathrm{mg} / \mathrm{L}$. The $\mathrm{R}^{2}$ was 0.90 


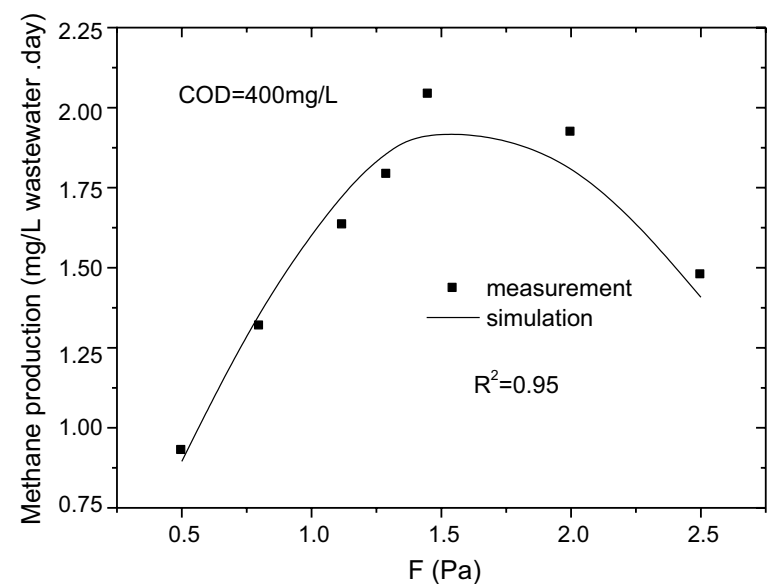

Fig. 9 Methane production vs wall-shear stress, $C O D=400 \mathrm{mg} / \mathrm{L}$. The relationship between the methane production and wall-shear stress. The $\mathrm{R}^{2}$ value of Eq. (5) was 0.95 , indicating that the Eq. (5) was also reasonable

environments, terrestrial soils and saline lakes including deep sea methane seep sediments (Nunoura et al. 2011). The distribution of DHVEG-6 indicated that it could produce methane in this study, though the physiological and metabolic functions of DHVEG-6 were not fully known (Kuroda et al. 2014). Methanospirillum was a fastidious anaerobic specie and could produce methane with $\mathrm{H}_{2}-$ $\mathrm{CO}_{2}$, and its preferred living temperature and $\mathrm{pH}$ were $30.0-37.0^{\circ} \mathrm{C}$ and $6.6-7.4$, respectively (Ferry et al. 1974).

In fact, the proportion of Methanospirillum in sewer biofilm increased with the increase of wall-shear stress, but the amount was not, because that the microorganism amount did not increase with the increase of wall-shear stress. Although the proportion of Methanospirillum in sewer biofilm cultured at wall-shear stress of $1.45 \mathrm{~Pa}$ was not the highest, the amount of Methanospirillum was at the most. To be exact, the more Methanospirillum was, the greater methane production was and it implied that Methanospirillum played the crucial role in methane formation in gravity sewers in this study.

\section{Model development and validation}

Methane production is related directly to the amount of microorganism which is influenced by wall-shear stress in sewers. So the wall-shear stress could play an important role in methane production. The aims of model was to make certain of the role that wall-shear stress played in methane production (Ai et al. 2016; Chaosakul et al. 2014).

$$
\begin{aligned}
& \mathrm{X}=-0.0485 F^{2}+0.161 F-0.0142 \\
& Q_{C H_{4}}=Y_{C_{4} / X} \cdot X \cdot \theta^{T-20} \cdot H R T .
\end{aligned}
$$

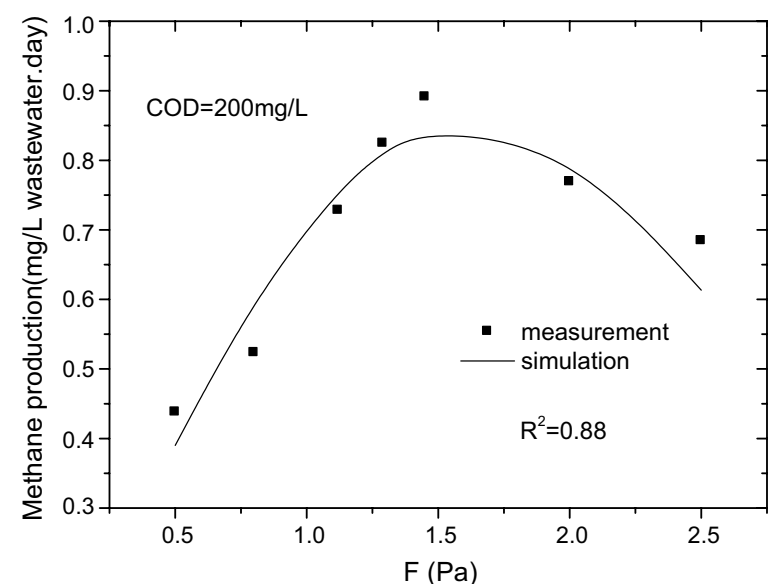

Fig. 10 Methane production vs wall-shear stress, $C O D=200 \mathrm{mg} / \mathrm{L}$. In order to validate the model, the measured data was used when COD was $200 \mathrm{mg} / \mathrm{L}$. The fitting results were showed. Results showed the model's predictions, agreed with the measurements well, the difference between measurement and simulation was found in the rage of 1.5-13.0\%. In this model, substrate concentration and pipe size were not considered that leaded to some errors between measurement and simulation. And it would be revised in our future research

$$
\begin{aligned}
\mathrm{F}= & 0.21941+0.44146 \mathrm{I}+1.73331 \mathrm{n}-0.52041 \mathrm{v} \\
& +0.13167 \mathrm{nI}-0.24688 \mathrm{vI}-1.47281 \mathrm{nv} \\
& +0.23833 I^{2}-0.12750 n^{2}+1.88828 v^{2}
\end{aligned}
$$

where $Q_{\mathrm{CH}_{4}}$ is the methane production, $\mathrm{mg} /(\mathrm{L}$ wastewater day); $Y_{\mathrm{CH}_{4} / X}$ is the yield coefficient, mg methane/ $\mathrm{kg}$ biomass; $\mathrm{X}$ is the amount of microorganism, $\mathrm{kg} ; \theta$ is the temperature coefficient $=1.05$; $\mathrm{T}$ is the temperature of sewer wastewater, ${ }^{\circ} \mathrm{C}$; HRT is the wastewater retention time, $\mathrm{h}$; F is the wall-shear stress, $\mathrm{Pa}$; I is the slope of sewers, \%; $\mathrm{n}$ is the fullness degree of sewers; $\mathrm{v}$ is the velocity of flow, $\mathrm{m} / \mathrm{s}$.

Equation (5) was similar to the model previously proposed by Chaosakul et al. (2014) except that the $X$ and $Y_{\mathrm{CH}_{4} / X}$ took the place of (A/V) and $\gamma$ (the specific rate of $\mathrm{CH}_{4}$ emission), respectively and Eq. (3) was based on our previous study (Ai et al. 2016).

Figure 9 illustrated the relationship between the methane production and wall-shear stress. The $R^{2}$ value of Eq. (5) was 0.95, indicating that the Eq. (5) was also reasonable.

In order to validate the model, the measured data was used when COD was $200 \mathrm{mg} / \mathrm{L}$. The fitting results were showed in Fig. 10. Results showed the model's predictions, agreed with the measurements well, the difference between measurement and simulation was found in the rage of $1.5-13.0 \%$. In this model, substrate concentration and pipe size were not considered that leaded to some 
errors between measurement and simulation. And it would be revised in our future research.

Most of methanogen was strictly anaerobic and a small amount of methanogen was anoxic and aerobic. According to the laying of gravity sewer, there are manholes among the sewers. Usually, there is oxygen in gravity sewers. In this study, the methane production was less than which obtained in rising main sewers in previous research (Guisasola et al. 2008, 2009). An important reason may be that anaerobic environment in rising main sewers is more beneficial to methane production. In addition, rising main sewers were full of sewage so that biofilm could develop on the entire surface of sewers. There is an obvious difference between gravity sewer and rising main sewer. Gravity sewers are not full of sewage. The biofilm could not grow on the places which are not covered with sewage. This would lead to difference in microorganism amount and that affects the methane production.

\section{Authors' contributions}

$\mathrm{HA}$ and $\mathrm{QH}$ : experiment design and manuscript writing guide. JX: reactor construct and manuscript write. $\mathrm{HL}, \mathrm{CY}$ and $\mathrm{YW}$ : experiment test and data analysis. All authors read and approved the final manuscript.

\section{Author details}

${ }^{1}$ Chongqing Huantou Environmental Big Data Service \& Environmental Engineering Co. Ltd, A1 District, Milan Street, Yubei District, Chongqing 401123, People's Republic of China. ${ }^{2}$ Key Laboratory of the Three Gorges Reservoir Region's Eco-Environment, Ministry of Education, Chongqing University, Chongqing 400045, People's Republic of China. ${ }^{3}$ Transportation Design \& Research Sub-Institute, Southwest Municipal Engineering Design \& Research Institute of China, Star Road No. 11, Chengdu, Sichuan 610081, People's Republic of China.

\section{Acknowledgements}

Not applicable.

\section{Competing interests}

The authors declare that they have no competing interests.

\section{Availability of data and materials}

Not applicable.

\section{Consent for publication}

Not applicable.

\section{Ethics approval and consent to participate}

This article does not contain any studies with human participants or animals performed by any of the authors.

\section{Funding}

This work was supported by Natural Science Funding of China Project (51108480 and 51478061) and by Program for Innovative Research Team in University in Chongqing (CXTDX201601003).

\section{Publisher's Note}

Springer Nature remains neutral with regard to jurisdictional claims in published maps and institutional affiliations.

Received: 27 October 2017 Accepted: 16 February 2018

Published online: 07 March 2018

\section{References}

Ai H, Xu J, Huang W, He Q, Ni B, Wang Y (2016) Mechanism and kinetics of biofilm growth process influenced by shear stress in sewers. Water Sci Technol 73(7):1572-1582. https://doi.org/10.2166/wst.2015.633

Casamayor EO, Triadó-Margarit X, Castañeda C (2013) Microbial biodiversity in saline shallow lakes of the Monegros Desert, Spain. FEMS Microbiol Ecol 85(3):503-518

Chaosakul T, Koottatep T, Polprasert C (2014) A model for methane production in sewers. J Environ Sci Health Part A Tox Hazard Subst Environ Eng 49(11):1316-1321. https://doi.org/10.1080/10934529.2014.910071

Cheng SS, Chen WC, Hwang HH (1997) Biofilm formation: the effects of hydrodynamic and substrate feeding patterns in three phase draft-tube fluidized bed for nitrification process. Water Sci Technol 36(12):83-90

Christensen BE, Characklis WG (1990) Physical and chemical properties of biofilms. Biofilms:93-130

El-Fadel M, Massoud M (2001) Methane emissions from wastewater management. Environ Pollut 114(2):177-185. https://doi.org/10.1016/ s0269-7491(00)00222-0

Ferry JG, Smith PH, Wolfe R (1974) Methanospirillum, a new genus of methanogenic bacteria, and characterization of Methanospirillum hungatii sp. nov. Int J Syst Bacteriol 24(4):465-469

Foley J, Yuan Z, Lant P (2009) Dissolved methane in rising main sewer systems: field measurements and simple model development for estimating greenhouse gas emissions. Water Sci Technol 60(11):2963-2971. https:// doi.org/10.2166/wst.2009.718

Ganigue R, Yuan Z (2014) Impact of oxygen injection on $\mathrm{CH}_{4}$ and $\mathrm{N}_{2} \mathrm{O}$ emissions from rising main sewers. J Environ Manage 144:279-285. https:// doi.org/10.1016/j.jenvman.2014.04.023

Ganigue R, Gutierrez O, Rootsey R, Yuan Z (2011) Chemical dosing for sulfide control in Australia: an industry survey. Water Res 45(19):6564-6574. https://doi.org/10.1016/j.watres.2011.09.054

Guisasola A, de Haas D, Keller J, Yuan Z (2008) Methane formation in sewer systems. Water Res 42(6-7):1421-1430. https://doi.org/10.1016/j. watres.2007.10.014

Guisasola A, Sharma KR, Keller J, Yuan Z (2009) Development of a model for assessing methane formation in rising main sewers. Water Res 43(11):2874-2884

Guzmán K, La Motta EJ, McCorquodale JA, Rojas S, Ermogenous M (2007) Effect of biofilm formation on roughness coefficient and solids deposition in small-diameter PVC sewer pipes. J Environ Eng 133(4):364-371

Jiang G, Sharma KR, Yuan Z (2013) Effects of nitrate dosing on methanogenic activity in a sulfide-producing sewer biofilm reactor. Water Res 47(5):1783-1792

Kuroda K, Hatamoto M, Nakahara N, Abe K, Takahashi M, Araki N, Yamaguchi $\mathrm{T}$ (2015) Community composition of known and uncultured archaeal lineages in anaerobic or anoxic wastewater treatment sludge. Microb Ecol 69(3):586-596

Kwok WK, Picioreanu C, Ong SL, van Loosdrecht MCM, Ng WJ, Heijnen JJ (1998) Influence of biomass production and detachment forces on biofilm structures in a biofilm airlift suspension reactor. Biotechnol Bioeng 58(4):400-407

Laspidou CS, Rittmann BE (2004) Modeling the development of biofilm density including active bacteria, inert biomass, and extracellular polymeric substances. Water Res 38(14-15):3349-3361. https://doi.org/10.1016/j. watres.2004.04.037

Liu Y, Tay JH (2002) The essential role of hydrodynamic shear force in the formation of biofilm and granular sludge. Water Res 36(7):1653-1665. https://doi.org/10.1016/s0043-1354(01)00379-7

Nunoura T, Takaki Y, Kazama H, Hirai M, Ashi J, Imachi H, Takai K (2011) Microbial diversity in deep-sea methane seep sediments presented by SSU rRNA gene tag sequencing. Microbes Environ JSME 27(4):382-390

Rochex A, Godon J-J, Bernet N, Escudié R (2008) Role of shear stress on composition, diversity and dynamics of biofilm bacterial communities. Water Res 42(20):4915-4922

Sawakuchi HO, Bastviken D, Sawakuchi AO, Ward ND, Borges CD, Tsai SM, Richey JE, Ballester MVR, Krusche AV (2016) Oxidative mitigation of aquatic methane emissions in large Amazonian rivers. Global Change Biol 22(3):1075-1085. https://doi.org/10.1111/gcb.13169

Sharma KR, Corrie S, Yuan Z (2012) Integrated modelling of sewer system and wastewater treatment plant for investigating the impacts of chemical 
dosing in sewers. Water Sci Technol 65(8):1399-1405. https://doi. org/10.2166/wst.2012.019

Smolders GJF, Vandermeij J, Vanloosdrecht MCM, Heijnen JJ (1994) Model of the anaerobic metabolism of the biological phosphorus removal process - stoichiometry and pH influence. Biotechnol Bioeng 43(6):461-470. https://doi.org/10.1002/bit.260430605

van Loosdrecht MCM, Heijnen JJ, Eberl H, Kreft J, Picioreanu C (2002) Mathematical modelling of biofilm structures. Antonie Van Leeuwenhoek Int J General Mol Microbiol 81(1-4):245-256. https://doi.org/10.102 3/a:1020527020464

vanLoosdrecht MCM, Eikelboom D, Gjaltema A, Mulder A, Tijhuis L, Heijnen JJ (1995) Biofilm structures. Water Sci Technol 32(8):35-43. https://doi. org/10.1016/0273-1223(96)00005-4

Vieira MJ, Melo LF, Pinheiro MM (1993) Biofilm formation: hydrodynamic effects on internal diffusion and structure. Biofouling 7(1):67-80

Weller S, Janz B, Jorg L, Kraus D, Racela HSU, Wassmann R, Butterbach-Bahl K, Kiese R (2016) Greenhouse gas emissions and global warming potential of traditional and diversified tropical rice rotation systems. Global Change Biol 22(1):432-448. https://doi.org/10.1111/gcb.13099

Xin X, He J, Wang Y, Feng J, Qiu W (2016) Role of aeration intensity on performance and microbial community profiles in a sequencing batch reaction kettle (SBRK) for wastewater nutrients rapid removal. Bioresour Technol 201:140-147. https://doi.org/10.1016/j.biortech.2015.11.053

Xu J, Li M, He Q, Sun X, Zhou X, Su Z, Ai H (2017) Effect of flow rate on growth and oxygen consumption of biofilm in gravity sewer. Environ Sci Pollut Res 24(1):1-9

Zhang L, Keller J, Yuan Z (2009) Inhibition of sulfate-reducing and methanogenic activities of anaerobic sewer biofilms by ferric iron dosing. Water Res 43(17):4123-4132

Zhao X, Liu SL, Pu C, Zhang XQ, Xue JF, Zhang R, Wang YQ, Lal R, Zhang HL, Chen $F$ (2016) Methane and nitrous oxide emissions under no-till farming in China: a meta-analysis. Global Change Biol 22(4):163-170

\section{Submit your manuscript to a SpringerOpen ${ }^{\circ}$ journal and benefit from:}

- Convenient online submission

- Rigorous peer review

- Open access: articles freely available online

- High visibility within the field

- Retaining the copyright to your article

Submit your next manuscript at $\boldsymbol{\nabla}$ springeropen.com 